\title{
Therapeutic Abortion Procedure
}

National Cancer Institute

\section{Source}

National Cancer Institute. Therapeutic Abortion Procedure. NCI Thesaurus. Code C92894.

Intentional end of pregnancy by the removal or expulsion of a fetus or embryo from the uterus to preserve the health of the gravida (pregnant female). 